\title{
Pendugaan Mineralisasi Emas Menggunakan Metode Magnetik di Nagari Lubuk Gadang Kecamatan Sangir, Solok Selatan, Sumatera Barat
}

\author{
Fikri Firmansyah*, Arif Budiman \\ Laboratorium Fisika Bumi, Jurusan Fisika, FMIPA, Universitas Andalas \\ Kampus Unand, Limau Manih, Padang, 25163 \\ *fikrifirmansyah096@gmail.com
}

\begin{abstract}
ABSTRAK
Telah dilakukan penelitian tentang pendugaan mineralisasi emas di Nagari Lubuk Gadang, Kecamatan Sangir, Solok Selatan, Sumatera Barat. Penelitian ini menggunakan metode magnetik dengan tahapan yaitu akuisisi data lapangan, pengolahan data dan interpretasi data. Alat yang digunakan adalah Earth Magnetometer EM2 (Microteslas) AlphaLab.Inc. Perangkat lunak yang digunakan untuk membuat peta kontur adalah software Surfer 11 dan pemodelan 2D menggunakan software Mag2dc. Pengukuran medan magnetik dilakukan pada 50 titik pengamatan dengan luas daerah $670 \mathrm{~m}^{2}$. Hasil penelitian menunjukkan bahwa ditemukan mineral pembawa emas yaitu pirit dengan suseptibilitas magnetik $0.000035-0.005$ SI, kalkopirit dengan suseptibilitas magnetik $0.000023-0.0004$ SI, troilit dengan suseptibilitas magnetik $0.00061-0.0017$ SI, pirhotit dengan suseptibilitas magnetik $0.00046-1.4$ SI, dan siderit dengan suseptibilitas magnetik $0.0013-0.011$ SI merupakan mineral sulfida magmatik yang terdapat dalam batuan metamorf dan sedimen. Disamping itu mineral emas juga berasosiasi dengan mineral magnetik yaitu batuan beku (intrusi) yaitu porfiri dengan suseptibilitas magnetik $0.00025-0.21$ SI. Zona mineralisasi emas diperkirakan terletak pada kedalaman 5 meter sampai dengan 35 meter di bawah permukaan tanah.

Kata kunci: Metode magnetik, mineralisasi emas, suseptibilitas.
\end{abstract}

\section{ABSTRACT}

The research about estimation gold mineralization using magnetic method in Nagari Lubuk Gadang, Kecamatan Sangir, Solok Selatan, West Sumatera has been done. The tool used is Earth Magnetometer EM2 (Microteslas) AlphaLab.Inc. The software used to create maps is Surfer 11 software and 2D modeling using Mag2dc software. Magnetic field measurements were carried out on 50 observation points with an area of $670 \mathrm{~m}^{2}$. The results showed that gold pyrite carrier minerals with magnetic susceptibility of $0.000035-0.005$ SI, chalcopyrite with magnetic susceptibility $0.000023-0.0004$ SI, troilite with magnetic susceptibility $0.00061-0.0017$ SI, pyrrhotite with magnetic susceptibility 0.00046 - 1.4 SI, and siderite with magnetic susceptibility 0.0013 - 0.011 SI are magmatic sulfide minerals found in metamorphic and sedimentary rocks. Besides that, gold minerals are also associated with magnetic minerals, namely and igneous rocks which are porphyry with magnetic susceptibility of 0.00025-0.21 SI. The gold mineralization zone is estimated to be located at a depth of 5 meters up to 35 meters below ground level.

Keywords: Magnetic Method, Gold Mineralization, susceptibility.

\section{PENDAHULUAN}

Indonesia secara geologis merupakan negara yang berada di titik pertemuan tiga lempeng litosfer yaitu Lempeng Indo-Australia, Eurasia dan Pasifik. Hal ini menyebabkan Indonesia memiliki aktifitas tektonik yang tinggi ditandai dengan pembentukan gunung, gempa bumi, tsunami, gunung meletus, dan benua. (Ulinna'mah, 2011).

Pembentukan pegunungan, aktivitas magma pada gunung api dan proses sedimentasi dalam periode yang lama menyebabkan terbentuknya endapan mineral sehingga Indonesia memiliki sumber daya mineral dan hasil tambang yang melimpah, salah satunya adalah emas. Berdasarkan data Kementerian Energi dan Sumber Daya Mineral (ESDM) Tahun 2013 Indonesia berada pada urutan ke sembilan sebagai negara produsen emas terbesar dunia dengan cadangan emas sebesar 3.000 ton dan sumber daya yang mencapai 6.000 ton. Potensi yang besar tersebut belum bisa dimanfaatkan secara maksimal dikarenakan proses prospeksi dan eksplorasi yang masih minim.

Eksplorasi mineral emas hampir tidak mungkin dilakukan secara langsung dikarenakan kandungan emas sangat kecil dalam lingkungan pengendapannya yaitu sekitar 2 - $30 \mathrm{~g} / \mathrm{ton}$. 
Pendeteksian dapat dilakukan dengan memprediksi keberadaan mineral yang biasanya menjadi petunjuk penting keberadaan mineralisasi emas. Mineral-mineral ini biasanya disebut dengan mineral pembawa emas yang merupakan mineral besi sulfida (iron sulfides) yaitu pirit $\left(\mathrm{FeS}_{2}\right)$, kalkopirit $\left(\mathrm{CuFeS}_{2}\right)$, troilit $(\mathrm{FeS})$, dan pirhotit $\left(\mathrm{Fe}_{1-\mathrm{x}} \mathrm{S}\right)$. Disamping itu mineral emas juga berasosiasi dengan mineral magnetik yaitu siderit $\left(\mathrm{FeCO}_{3}\right)$ dan batuan beku yaitu porfiri (Kahfi dan Yulianto, 2008).

Stuktur bumi dan eksplorasi mineral pertambangan dapat ditentukan dengan metode geofisika. Metode geofisika antara lain adalah metode seismik, geolistrik, gravity, magnetik dan lainnya. Metode magnetik digunakan dalam mendeteksi mineral yang memiliki sifat kemagnetan. Mineral pembawa emas merupakan mineral magnetik, maka metode magnetik lebih banyak digunakan dalam eksplorasi emas. Metode ini memanfaatkan sifat kemagnetan bumi yang disebabkan adanya perbedaan tingkat magnetisasi suatu batuan yang diinduksi oleh medan magnetik bumi (Ismail, 2010). Metode magnetik sering juga digunakan dalam eksplorasi minyak bumi, panas bumi, batuan mineral, serta diterapkan pada pencarian prospeksi benda benda arkeologi (Siahaan, 2009).

Junaedy dkk. (2016) melakukan penelitian di daerah Lokasi Tambang Emas Poboya, Provinsi Sulawesi Tengah menemukan mineral pembawa emas yaitu pirit dengan suseptibilitas $0.000035-0.005$ SI, kalkopirit dengan suseptibilitas $0.000023-0.0004$ SI, troilit dengan suseptibilitas $0.00061-0.0017$ SI, pirhotit dengan suseptibilitas $0.00046-1.4$ SI, porfiri dengan suseptibilitas $0.00025-0.21 \mathrm{SI}$, dan siderit dengan suseptibilitas $0.0013-0.011 \mathrm{SI}$ yang terletak pada kedalaman rata-rata antara $70 \mathrm{~m}$ sampai dengan $320 \mathrm{~m}$ di bawah permukaan tanah.

Menurut data Pertambangan Pemerintah Kabupaten Solok Selatan (2017), bahan tambang seperti, emas, timah hitam, biji besi, tembaga, mangan dan perak tersebar pada beberapa kecamatan. Nagari Lubuk Gadang Kecamatan Sangir memiliki penambangan emas yang belokasi di Hutan Batang Hulu yang digarap oleh PT. Andalas Merapi Timber (AMT). Perusahaan ini memegang izin hak pengusahaan hutan (HPH) hanya aktif sampai Tahun 2012. Setelah itu tambang tersebut dikelola oleh masyarakat sekitar secara illegal. Aktivitas penambangan emas oleh masyarakat dilakukan dengan cara menggali tanah dalam bentuk sumur-sumur yang diduga mengandung butiran biji emas secara tidak terencana. Penambangan emas yang tidak memperhatikan aspek-aspek kelestarian hutan ini, menyebabkan rusaknya infrastruktur dan ekosistem Hutan Batang Hulu (Vinolia, 2016). Oleh karena itu perlu dilakukan penelitian tentang pemetaan lokasi tersebarnya mineralisasi emas di daerah tersebut agar dapat ditindaklanjuti oleh pemerintah agar dapat ditambang secara resmi dan sebagai lapangan kerja dan sumber pendapatan daerah.

\section{METODE}

\subsection{Akuisisi Data}

Akuisisi atau pengambilan data medan magnetik yang digunakan adalah cara looping dikarenakan keterbatasan alat dan sumber daya manusia, sehingga satu alat digunakan sekaligus untuk mencatat variasi harian medan magnetik dan pengukuran medan magnetik di setiap titik pengukuran. Pengambilan data pengukuran dilakukan pada luas daerah $\pm 670 \mathrm{~m}^{2}$ dengan 50 titik pengambilan data.

Jarak ideal pengambilan data tiap pengambilan data adalah $5-10 \mathrm{~m}$, tetapi dikarenakan kondisi daerah yang tidak memungkinkan, yaitu banyak terdapat lobang besar bekas pertambangan sebelumnya maka sebagian data diambil secara acak (random) dengan menyesuaikan kondisi geografis, dapat dilihat pada Gambar 1.

Teknik pengambilan data yang dilakukan dengan looping diawali dengan melihat sudut deklinasi, inklinasi, ketinggian untuk pengolahan data saat reduksi ke kutub pada daerah tersebut yang dapat dilihat pada GPS. Pengukuran awal dilakukan dengan cara sensor diletakkan pada posisi titik pengambilan data yang telah ditentukan, medan magnetik akan terbaca pada display alat. Hasil pengukuran medan magnetik dicatat, begitu juga waktu pengukuran dan koordinat lokasi pada titik tersebut. Kegiatan ini dilakukan dengan 50 titik 
pengambilan data. Hasil dari suvei geomagnetik ini didapatkan data induksi magnetik total yang akan dilakukan pengolahan lanjutan.

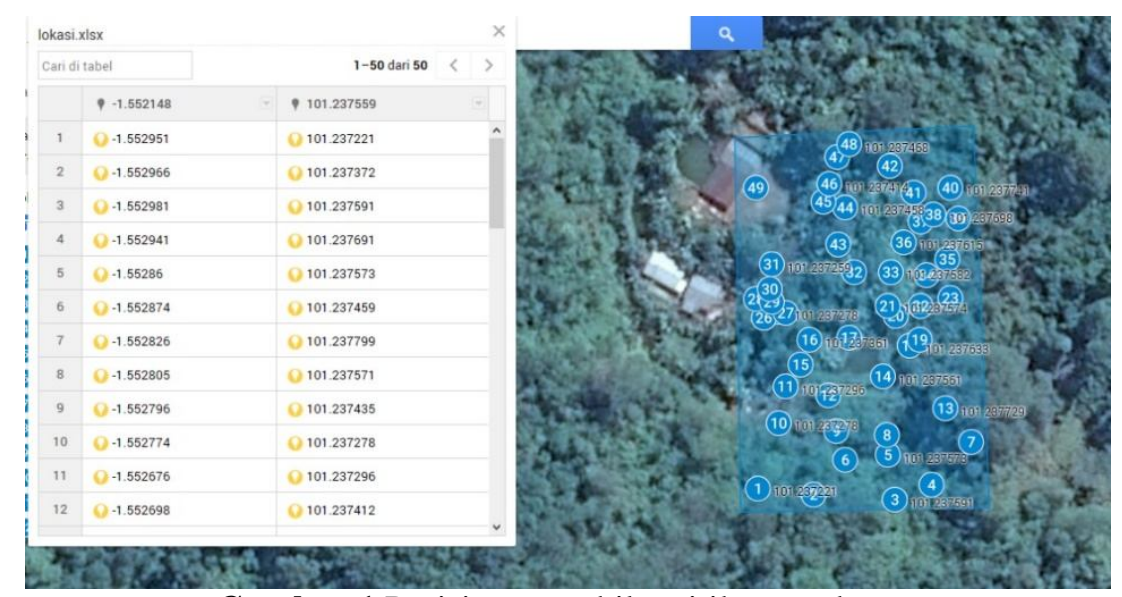

Gambar 1 Posisi pengambilan titik pengukuran

\subsection{Pengolahan data}

Pengolahan data diawali dengan pembuatan peta kontur induksi medan magnetik total yang di dapat dari hasil akuisisi data magnetik, selanjutnya melakukan koreksi diurnal dan IGRF (International Geomagnetic Reference Field) untuk mendapatkan nilai anomali medan magnetik total dengan menggunakan Persamaan (1).

$$
\Delta \mathrm{H}=\mathrm{H}_{\mathrm{p}}-\mathrm{H}_{\mathrm{IGRF}} \pm \mathrm{H}_{\mathrm{d}}
$$

dengan $\Delta H$ adalah anomali magnetik total, $H_{p}$ adalah medan magnetik hasil pengukuran, $H_{I G R F}$ adalah medan magnetik IGRF, dan $H_{d}$ adalah koreksi diurnal. Nilai anomali magnetik total interpretasikan dalam peta kontur, kemudian dilakukan koreksi kontinuitas ke atas dan reduksi ke kutub untuk mendapatkan pemisahan anomali magnetik regional dan anomali magnetik residual. Peta kontur anomali magnetik residual hasil pemisahan anomali tersebut selanjutnya dilakukan slice sebanyak 2 bagian dengan bentuk diagonal agar mencapai seluruh daerah medan anomali magnetik. Hasil slice tersebut dijabarkan dengan pemodelan 2D menggunakan software Mag2dc.

\subsection{Interpretasi Data}

Interpretasi data dilakukan terhadap hubungan anomali magnetik residual dengan nilai suseptibilitas batuan yang terdapat di bawah permukaan daerah penelitian. Nilai suseptibilitas tersebut didapat dengan menggunakan software Mag2dc yaitu menggambarkan prediksi bentuk dan jenis mineral di bawah permukaan tersebut. Nilai suseptibilitas ini yang dicocokkan dengan nilai suseptibilitas mineral literatur yang sudah ada. Selain itu interpretasi dilakukan dengan asumsi: (1) terdapat sebaran mineral pembawa unsur emas dan (2) dapat dilihat potensi mineral pembawa unsur emas di daerah tersebut. Setelah mengetahui nilai suseptibilitas dari setiap batuan yang terindentifikasi kemudian dicocokan dengan literatur dan dilakukan analisis hubungan nilai suseptibilitas dengan jenis batuannya. Tahap akhir membandingkan jenis mineral dan batuan hasil pemodelan 2D dengan peta geologi daerah penelitian.

\section{HASIL DAN DISKUSI}

\subsection{Hasil Pengolahan Data Magnetik}

\subsubsection{Anomali Medan Magnetik Total}

Nilai anomali medan magnetik total yang didapat dari hasil koreksi diurnal dan nilai IGRF yang di dapat dari website NOAA yaitu 42.944,4 nT. Hasil koreksi nya dapat dilihat pada peta kontur pada Gambar 2. 


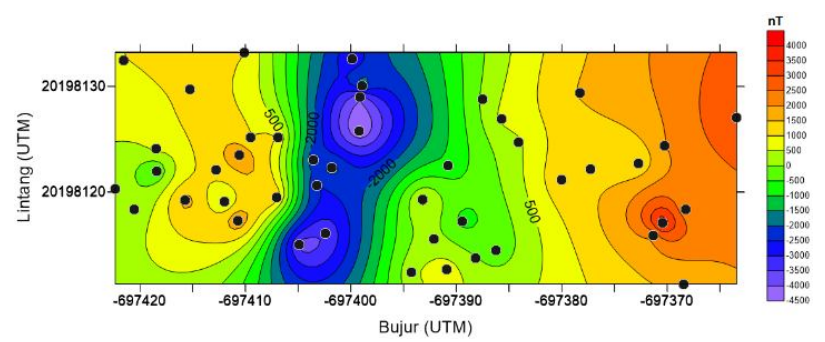

Gambar 2 Peta kontur anomali medan magnetik total

Nilai anomali medan magnetik terlihat lebih kecil dari medan magnetik total setelah dilakukan koreksi yang berkisar antara $-4.500 \mathrm{nT}$ sampai $4.000 \mathrm{nT}$. Bagian barat daerah penelitian memiliki masih klosur medan magnetik sedang dengan rentang -1000 nT sampai $1500 \mathrm{nT}$. Klosur rendah masih terdapat pada pertengahan daerah penelitian yang memiliki rentang -4500 nT sampai $-1500 \mathrm{nT}$. Klosur tinggi masih terdapat pada bagian timur deerah penelitan dalam rentang $500 \mathrm{nT}$ sampai $4000 \mathrm{nT}$.

\subsubsection{Anomali Medan Magnetik Total Hasil Kontinuasi ke Atas}

Pada penelitian ini dilakukan empat kali proses kontinuasi dimana data ditransformasi pada ketinggian $25 \mathrm{~m}, 50 \mathrm{~m}, 75 \mathrm{~m}$, dan $100 \mathrm{~m}$. Proses kontinuasi ke atas dirasa cukup bila fitur anomali yang menjadi target penelitian sudah tidak lagi mengalami perubahan yang signifikan dan sudah tidak lagi menampilan klosur klosur anomali yang rapat dan sempit. Hasil kontinuasi pada ketinggian $100 \mathrm{~m}$ digunakan untuk pengolahan selanjutnya karena telah menampilkan anomali regional yang homogen. Data anomali magnetik residual dapat dilihat pada Gambar 3, yang didapat dari koreksi kontinuitas keatas selanjutnya akan dikoreksi terhadap data anomali medan magnetik total yang akhirnya akan didapatkan medan anomali magnetik residual dengan besar medan magnet dalam rentang -5000 nT sampai $3500 \mathrm{nT}$.

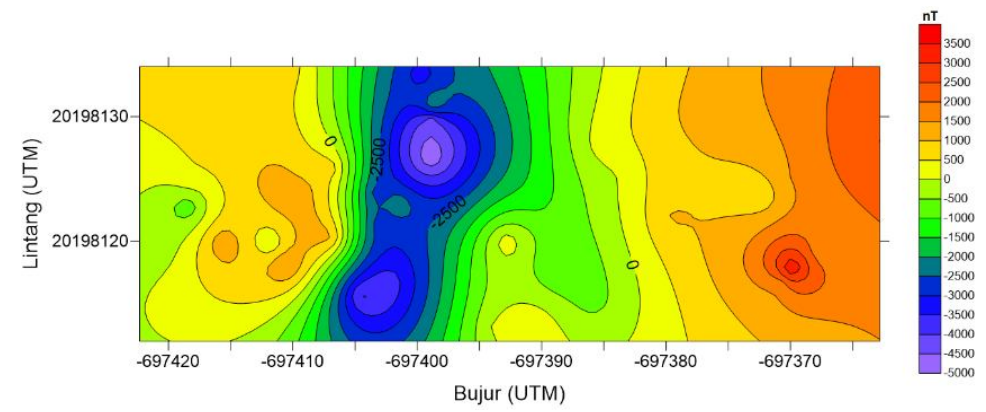

Gambar 3 Medan magnetik anomali residual

Anomali magnetik residual masih bersifat dipol dimana fitur anomali masih belum tepat berada di atas sumber anomali. Proses reduksi ke kutub diperlukan untuk melokalisasi keberadaan sumber anomali pada daerah penelitian. Data yang digunakan dalam proses reduksi ke kutub adalah nilai anomali magnetik hasil kontinuasi $100 \mathrm{~m}$.

\subsubsection{Anomali Medan Magnetik Total Hasil Reduksi ke Kutub (RTP)}

Data anomali medan magnetik yang telah di-RTP ditunjukkan pada Gambar 4. Peta kontur hasil reduksi ke kutub ini diterapkan 2 buah sayatan atau slice di sepanjang peta kontur yang melewati semua penyimpangan nilai medan magnet yang teridentifikasi, agar nantinya dapat kita prediksi bentuk bawah permukaan dan jenis batuannya. Terdapat perubahan rentang nilai anomali medan magnetik sebelum dan sesudah dilakukan proses RTP. Nilai anomali medan magnetik RTP nilainya berkisar -17000 sampai 10000 nT. 


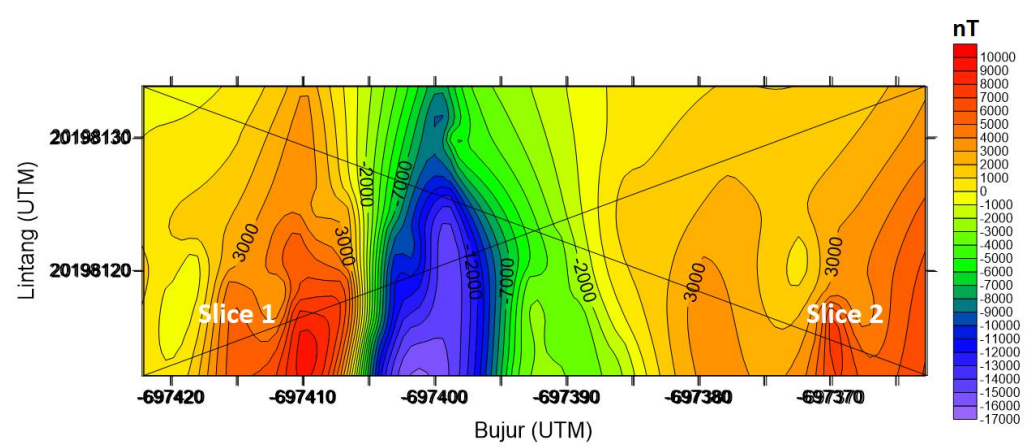

Gambar 4 Peta kontur hasil reduksi ke kutub

Klosur tinggi ditunjukkan dengan warna kuning - merah dengan rentang nilai 1000 sampai 10000 nT berada di sebelah barat kawasan penelitian, klosur sedang berwarna hijau dengan rentang nilai -1000 sampai $-8000 \mathrm{nT}$ berada di bagian tengah, dan klosur rendah dengan warna biru dengan rentang nilai -10000 sampai $-17000 \mathrm{nT}$ berada di tengah kawasan penelitian.

\subsection{Pemodelan 2D}

Berdasarkan hasil pemodelan Mag2dc yang telah dilakukan dapat dilihat bahwa strukur dari batuan dan mineral tidak beraturan dikarenakan mengalami proses tektonik Gambar 5 dan 6. Nilai suseptibilitas negatif merupakan respon dari mineral non-magnetik. Jenis mineral nonmagnetik tidak dapat di tentukan karena tidak terdapat kesesuaian antara nilai suseptibilitas dalam literatur. Sedang untuk benda yang memiliki respon suseptibilitas positif dapat ditentukan jenis batuan/mineral karena ada kesesuaian nilai suseptibilitas dalam literatur.

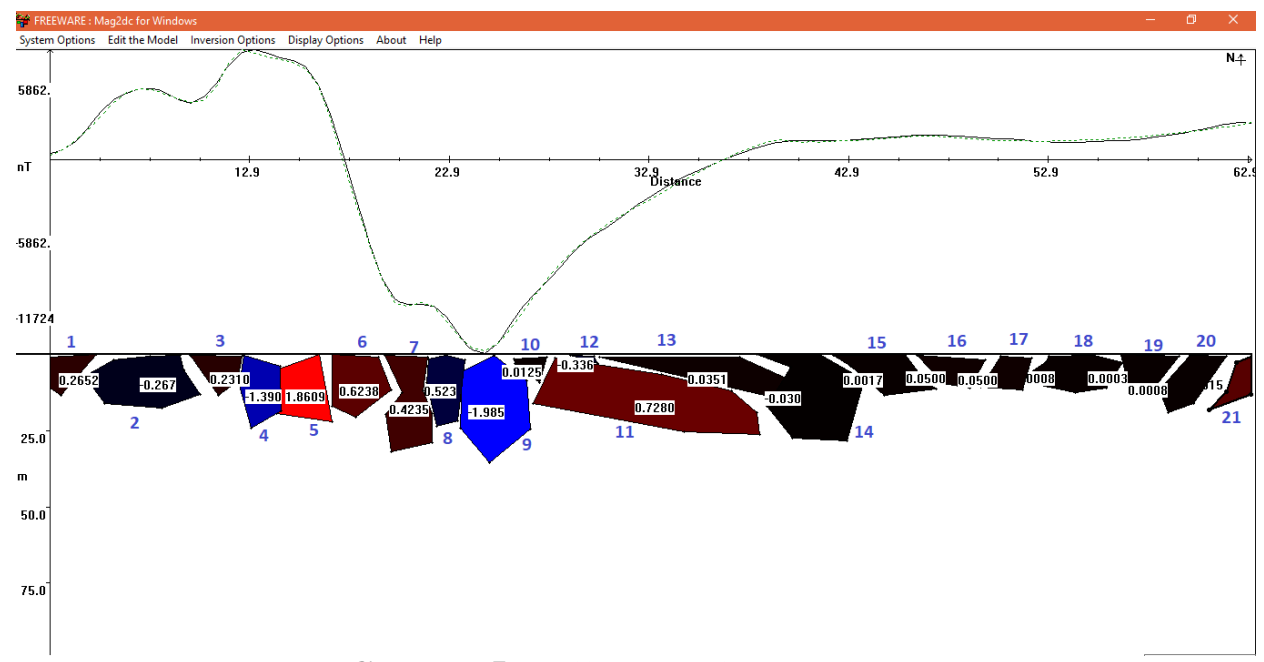

Gambar 5 Hasil Pemodelan 2D Slice 1

Prediksi variasi jenis batuan atau mineral yang terdeteksi dapat dilihat berdasarkan perbedaan warna dan nilai suseptibilitasnya. Terdapat 21 variasi jenis batuan pada slice 1 dan 17 variasi jenis batuan pada slice 2 dengan berbeda bentuk, warna, dan nilai suseptibilitasnya. Pada slice 1 nilai suseptibilitas yang tertinggi terdapat pada nomor 5 dengan nilai 1.8609 SI yaitu berwarna merah, yang terendah terdapat pada nomor 9 dengan nilai suseptibilitas -1.9850 SI dengan warna biru terang. 


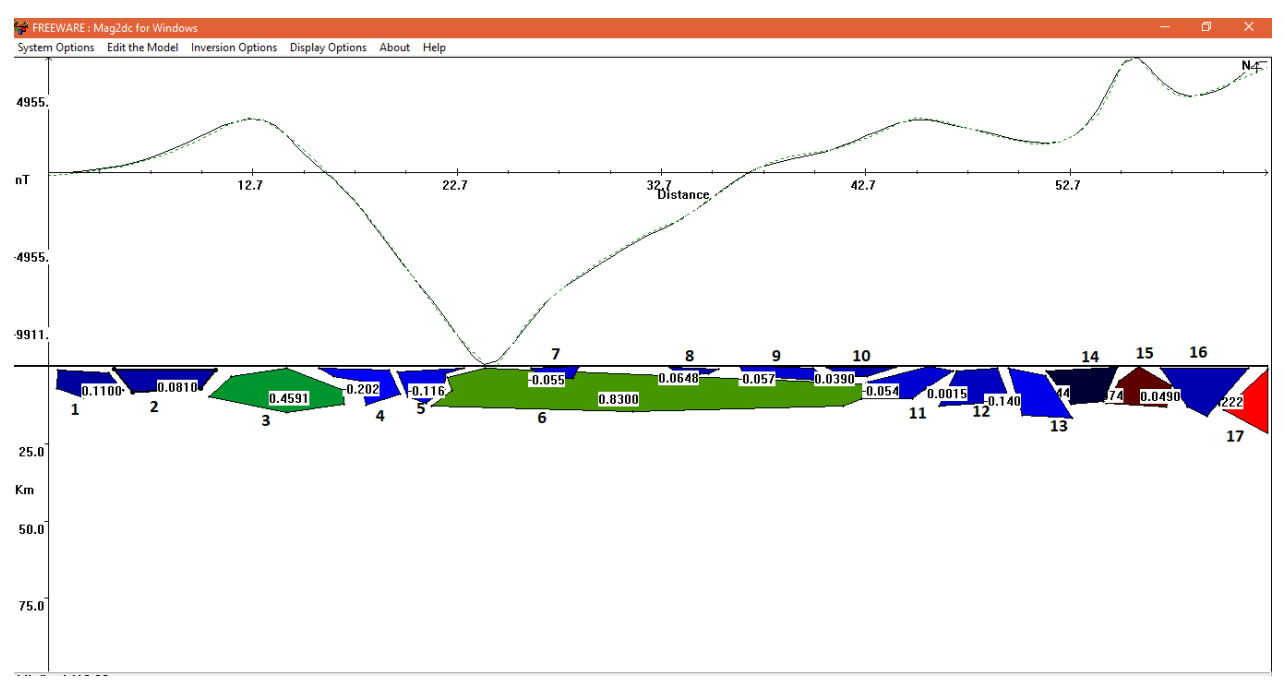

Gambar 6 Hasil Pemodelan 2D Slice 2

Pada slice 2 nilai suseptibilitas yang tertinggi terdapat pada nomor 17 dengan nilai 1.4222 SI yaitu berwarna merah, yang terendah terdapat pada nomor 4 dengan nilai suseptibilitas -0.2020 SI dengan warna biru terang. Ini menunjukkan adanya perbedaan yang signifikan dari nilai suseptibilitas batuan yang teridentifikasi untuk di bandingkan dengan literatur.

\subsection{Interpretasi Jenis Batuan/Mineral Terhadap Nilai Suseptibilitas}

Interpretasi dugaan bentuk bawah tanah dengan menggunakan Mag2dc dapat menampilkan bentuk batuan / mineral dan nilai suseptibilitasnya. Literatur nilai suseptibilitas batuan merujuk pada tabel Hunt dan Moskowitz, 1995.

Hasil interpretasi dan pengolahan data menggunakan Mag2dc pada slice 1 menghasilkan 21 prediksi bentuk batuan yang mempunyai nilai suseptibilitas yang berbeda beda. Batuan nomor 1, 3, 7 dan 8 dapat kita identifikasi sesuai literatur adalah mineral Porfiri atau Pirhotit. Batuan dengan nomor 6, 11, dan 21 yang berdasarkan literatur teridentifikasi sebagai mineral Pirhotit. Batuan dengan nomor 2, 4, 5, 12, dan 14 merupakan mineral non magnetik karena memiliki respon negatif. Batuan dengan nomor 10, 13, 16 dan 17 berdasarkan literatur teridentifikasi sebagai mineral Porfiri, dan Pirhotit. Batuan nomor 15, 18, 19, dan 20 yang berdasarkan litertur terindeksi sebagai Pirit, Siderit, Porfiri, Troilit, Pirhotit, Kalkopirit.

Hasil interpretasi pada slice 2 menghasilkan 17 prediksi bentuk batuan yang mempunyai nilai suseptibilitas yang berbeda beda. Batuan nomor 3 dan 14 dapat kita identifikasi sesuai literatur adalah mineral Pirhotit dan Titanomagnetik. Batuan dengan nomor 6 dan 15 yang berdasarkan literatur terindntifikasi sebagai mineral Pirhotit. Batuan dengan nomor 4, 5, 7, 9, 11 dan 13 merupakan mineral non magnetik karena memiliki respon negatif. Batuan dengan nomor 1, 2, 8, 10 dan 16 berdasarkan literatur teridentifikasi sebagai mineral Porfiri, dan Pirhotit, dan batuan nomor 12 memiliki yang berdasarkan litertur terindeksi sebagai Pirit, Siderit, Porfiri, Troilit, Pirhotit, Kalkopirit.

Bardasarkan literatur, batuan atau mineral tersebut adalah mineral pembawa emas yang berasosiasi dengan batuan beku, besi sulfida dan mineral magnetik yang memiliki kedalaman 5 meter sampai 35 meter di bawah permukaan tanah.

Berdasarkan peta geologi (Gambar 7), batuan yang terdapat di daerah penelitian adalah batuan sedimen dan metamorf yang tersusun atas formasi barisan $(\mathrm{Pb})$. Formasi Barisan $(\mathrm{Pb})$ tersusun atas batuan phyllite, slate, limestone, dan metagraywacke. Mineral penyusun phyllite adalah muskovit, serisit, klorit dan kuarsa. Pada mineral kuarsa penyusun phyllite ini terdapat urat kuarsa sulfida magnetik yang mengandung emas dengan ketebalan mencapai $3500 \mathrm{~m}$. Selain batuan sedimen dan metamorf juga terdapat batuan intrusi yaitu granit yang tersusun atas mineral granit biotit, pofiri kuarsa dan granit grafik. Mineral porfiri diinterpretasikan sebagai ubahan silisifikasi dan mengandung emas. Jika dibandingkan antara data yang didapatkan pada 
penelitian dengan data dari peta geologi dapat disimpulkan bahwa pada daerah yang diteliti memang terdapat mineral pembawa emas.

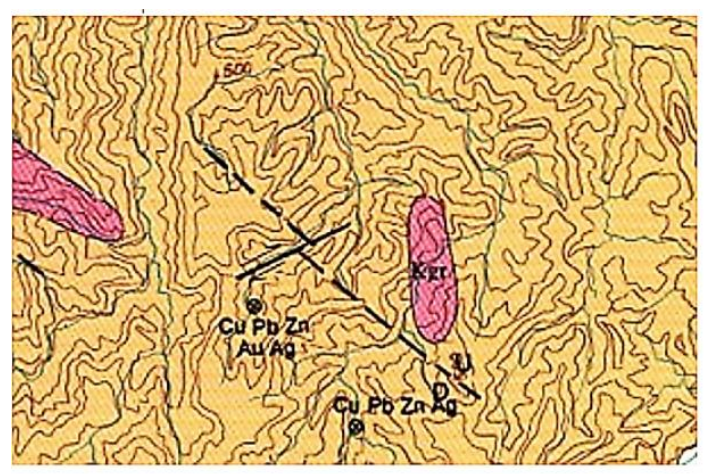

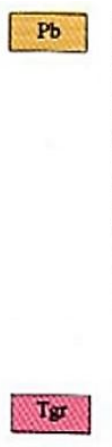

Gambar 7 Peta geologi daerah penelitian

FORMASI BARISAN : Filit batusabak, batugamping. betutanduk dan grewake meta. Filit terdiri dari muakovit serisit klorit dan kuarsa; sedikit turmalin, episol, zirkon dan grafit; setempat telah berikal terutama di jalux koyak dimana pendaursuryy berkembarg boik. Belahan butusabak unumrya berkembars beik. Rijarg benyak sekali terdapot Urat kuarsa sultida magmatik merzandurg emas terdapat di dacrah S. Sapat. Ketebalannya munigkin lebih dari $3500 \mathrm{~m}$.

BARIS.LV FORMATION : Phyllite, slate, imestone, horenfels, and meta grejwacke. Phyllite is composed of muscovite, sericite, chlorite, and quarts: minor tourmaline, epidote, :irvon and grophise: lacally kinked especially in. shear :ones where folluation is well developed. Slany clevage is commonly veins are found in S. Sapat Thiskmess is probably more than $3500 \mathrm{~m}$ BATUANINTRUSI INTRUSIVE ROCXS

g0 ORANIT : Oranit bioit, porfir kuana, and granit grafik. Oranit lerdapat sebegai irsi di dalem beaven plueon granodionit di doerah seboleh selatan 0 . Kerinci. Oranit ini dinyatakan benumur Miosen Tengah karene huburgarny dengan batuan pluton granodioxit GRANTE : Biotite granite, quarts porphyry and graphic granite. The granite arcurs as cores within granodionite stacks in the Area south of $G$. Kerinci. These granites are inferred to be of Middle Miacene age becaule of the ir association with the granodiorite stacks.

\section{KESIMPULAN}

Pada lokasi penelitian diduga emas berasosiasi dengan mineral pirit dengan suseptibilitas magnetik $0.000035-0.005$ SI, kalkopirit dengan suseptibilitas magnetik 0.000023 - 0.0004 SI, troilit dengan suseptibilitas magnetik $0.00061-0.0017$ SI, pirhotit dengan suseptibilitas magnetik 0.00046 - 1,4 SI, dan siderit dengan suseptibilitas magnetik 0.0013 0.011 SI merupakan mineral sulfida magmatik yang terdapat dalam batuan metamorf dan sedimen. Di samping itu mineral emas juga berasosiasi dengan batuan beku (intrusi) yaitu porfiri dengan suseptibilitas magnetik $0.00025-0.21$ SI. Diperkirakan zona mineralisasi emas terletak pada kedalaman 5 meter sampai dengan 35 meter di bawah permukaan tanah.

\section{DAFTAR PUSTAKA}

Hunt, C., Moskowitz, B. M., \& Banerje, S. K., (1995), Magnetic properties of rocks and minerals, In T. J. Ahrens (Ed.), Handbook of Physical Constants, (Vol. 3, pp. 189-204), American Geophysical Union.

Ismail, 2010, Metode Magnetik, Jurusan Fisika Fakultas Matematika Dan Ilmu Pengetahuan Alam Universitas Sebelas Maret, Surakarta.

Junaedy M., Efendi R., Sandra, 2016, Studi Zona Mineralisasi Emas Menggunakan Metode Magnetik Di Lokasi Tambang Emas Poboya, Online Journal of Natural Science Vol 5(2): 209-222.

Kahfi RA., Yulianto T., 2008, Identifikasi Struktur Lapisan Bawah Permukaan Daerah Manifestasi Emas Dengan Menggunakan Metode Magnetik Di Papandayan Garut Jawa Barat, Berkala Fisika, Vol 11(4): 127-135.

Siahaan, B., 2009, Penentuan Struktur Pada Zona Hydrokarbon Daerah "X" Menggunakan Metode Magnetik, Skripsi Program Geofisika Jurusan Fisika FMIPA, Universitas Indonesia.

Ulinna'mah, L., 2011, Identifikasi Struktur Geologi Menggunakan Metode Magnetik Di Daerah Prospek Emas Desa Tutugan Kabupaten Banyumas, Skripsi Program Studi Fisika, Fakultas Sains dan Teknik Jurusan MIPA Universitas Jenderal Soedirman, Purwokerto.

Vinolia. 2016. http://www.mongabay.co.id/2016/12/26/menyelisik-tambang-emas-ilegal-disolok-selatan/. 